\title{
Flora da Bahia: Cyclanthaceae
}

Juliana Gomes Freitas ${ }^{1 *}$, Eduardo da Silva Leal ${ }^{2}$, Ana Maria Giulietti ${ }^{1} \&$ Reyjane Patricia de Oliveira $^{1}$

${ }^{1}$ Departamento de Ciências Biológicas, Universidade Estadual de Feira de Santana, Av. Transnordestina, s.n., Novo Horizonte, 44036-900, Feira de Santana, Bahia, Brasil.

${ }^{2}$ Instituto de Pesquisas Jardim Botânico do Rio de Janeiro, Rua Pacheco Leão 915, 22460-030, Rio de Janeiro, RJ, Brasil.

\begin{abstract}
Resumo - É apresentado o levantamento de Cyclanthaceae para o estado da Bahia, Brasil. São reconhecidas quatro espécies nativas: Asplundia gardneri, A. maximiliani, Evodianthus funifer e Thoracocarpus bissectus, além de Carludovica palmata, introduzida no Estado. São apresentados chave de identificação, descrições, comentários para os táxons, além de ilustrações e mapas de distribuição das espécies na Bahia.
\end{abstract}

Palavras-chave adicionais: Carludovicoideae, Floresta Atlântica, Monocotiledôneas.

\begin{abstract}
Flora of Bahia: Cyclanthaceae) - A floristic treatment of the Cyclanthaceae from Bahia State, Brazil, is presented. Four native species in three genera are recognized: Asplundia gardneri, A. maximiliani, Evodianthus funifer and Thoracocarpus bissectus. Carludovica palmata, an introduced species, also occurs in the State. An identification key, descriptions and general comments on taxa as well as illustrations and distribution maps of species are presented.
\end{abstract}

Additional key words: Carludovicoideae, Atlantic forest, Monocots.

\section{Cyclanthaceae}

Ervas monoicas, terrestres ou lianescentes, hemiepífitas, raro epífitas; raízes aéreas ou grampiformes; caule aéreo curto ou desenvolvido, subterrâneo rizomatoso. Folhas simples, plicadas, dísticas ou espiraladas, pecioladas; lâmina inteira, flabeliforme ou bífida, raro palmada (Carludovica). Espádices terminais ou laterais, pedunculados. Flores homoclamídeas, raramente aclamídeas, unissexuadas, cada flor pistilada rodeada por quatro flores estaminadas (Carludovicoideae) ou flores estaminadas e pistiladas dispostas em anéis alternados (Cyclanthoideae); flores estaminadas com numerosas tépalas ou tépalas reduzidas, raro ausentes, simétricas ou assimétricas; receptáculo côncavo ou aplanado; anteras rimosas, basifixas; flores pistiladas livres ou lateralmente conatas, tépalas 4 , conatas ou livres, carpelos 4, estaminódios longos, filiformes, epipétalos; estiletes curtos ou sésseis, estigmas 4 . Infrutescências cilíndricas ou subesféricas, raro esféricas, verde-escuras, amareladas ou alaranjadas; bagas livres ou fundidas à espádice. Sementes pequenas, numerosas, achatadas ou cilíndricas, elípticas, ovaladas ou falciformes.

Distribuem-se na região neotropical, do sul do México até a bacia Amazônica e região Andina, e na costa atlântica brasileira, até Santa Catarina (Harling et al. 1998; Leitman \& Leal 2009; Leal 2010). Predominam em hábitats úmidos e sombreados de formações florestais, podendo ocorrer até $3000 \mathrm{~m}$ de altitude, e têm como centro de diversidade a Amazônia colombiana (Harling 1958).

Cyclanthaceae está dividida em duas subfamílias: Cyclanthoideae, incluindo apenas a espécie-tipo (Cyclanthus

*Autora para correspondência: julebiologia@gmail.com

Editor responsável: Alessandro Rapini

Submetido em: 5 jul. 2012; publicação eletrônica: 21 dez. 2012 bipartitus Poit.), caracterizada por apresentar as flores estaminadas e pistiladas dispostas em anéis alternados; e Carludovicoideae, compreendendo o restante da família. Inclui 12 gêneros, com número de espécie variando de 180 (Beck 2004) a 230 (Eriksson 2012). No Brasil, são registrados nove gêneros e 31 espécies, das quais 12 são endêmicas (Leal 2012). Ocorre, em sua maioria, nas Florestas Amazônica e Atlântica; na Caatinga, ocorre apenas uma espécie, Asplundia gardneri (Hook.) Harling, que também ocorre em enclaves de floresta perenifólia de altitude.

$\mathrm{Na}$ Bahia, a família está representada por quatro espécies nativas, distribuídas em três gêneros. Carludovica palmata Ruiz \& Pav., espécie introduzida, utilizada como ornamental em praças e/ou jardins, também é encontrada em margens de rodovias na região sul do Estado. Além disso, Asplundia tetragonopus (Mart. ex Drude) Harling foi descrita como proveniente da Bahia e reconhecida na lista do Brasil por Leal (2012) para o Estado. Segundo Harling (1958), essa espécie foi descrita com base em um material heterogêneo de procedência duvidosa. O holótipo (Martius $s / n$, Rio Itahypé, Bahia, depositado no herbário M) compreende dois espádices estéreis, mal preservados, misturados com uma folha e um espádice de E. funifer (Poit.) Lindm. Suas folhas, por outro lado, foram descritas e ilustradas com base em uma exsicata estéril (Martius $s / n$, depositada no herbário M) de localidade incerta. Portanto, é difícil afirmar que as folhas e os espádices dessas coleções pertençam à mesma espécie; não se sabe nem ao certo se esses materiais são oriundos da mesma localidade. O hábito de $A$. tetragonopus, de acordo com a descrição original, assemelha-se ao observado em $E$. funifer, enquanto os espádices do holótipo são relacionados por Harling (1958) aos de $A$. gardneri. Não se tem nenhum outro registro dessa espécie para o Brasil e nenhum outro material foi identificado como

Sitientibus série Ciências Biológicas 12(2): 193-200. 2012. 
A. tetragonopus desde então. Pela incerteza na delimitação da espécie e ausência de material para comprovar sua identidade, optou-se por não incluir Asplundia tetragonopus neste tratamento.

\section{Chave de identificação}

1. Inflorescências terminais, com espatas congestas abaixo do espádice 2.1. Evodianthus funifer

1'. Inflorescências axilares, com espatas dispostas ao longo do pedúnculo.

2. Lianas; espatas 6-8(-11), diminuindo de tamanho em direção à base do pedúnculo

3.1. Thoracocarpus bissectus

2'. Ervas, hemiepífitas ou terrestres; espatas 2-5, aumentando de tamanho em direção à base do pedúnculo. 3. Folhas palmadas .....Carludovica palmata (exótica) 3'. Folhas bífidas (bipartidas). ............. 1. Asplundia

4. Flores estaminadas assimétricas, receptáculo aplanado ............................. 1.1. A. gardneri

4'. Flores estaminadas simétricas, receptáculo côncavo 1.2. A. maximiliani

\section{Asplundia Harling}

Hemiepífitas com raízes grampiformes; caule aéreo desenvolvido ou rastejante, raro terrestres com caule muito curto. Folhas espiraladas, bipartidas, segmentos plicados, lanceolados a ovados, 1-3 nervuras, conspícuas na base da folha, ápice agudo ou raramente acuminado. Inflorescências axilares, elípticas, raro esféricas; espatas 3-5, lanceoladas a ovadas, raro cimbiformes, distribuídas ao longo do pedúnculo, aumentando de tamanho em direção à base. Flores estaminadas simétricas ou assimétricas; receptáculo côncavo ou aplanado; pedicelo excêntrico em flores assimétricas, lobos do perianto esbranquiçados, oblongos a obovados, portando glândulas; estames poucos a numerosos; conectivos filiformes, inconspícuos. Flores pistiladas lateralmente conatas, tépalas bem desenvolvidas, adnatas na base; estiletes 4, inconspícuos, livres; estigma de formas variadas. Bagas conatas lateralmente. Sementes pequenas, aplanadas, ovadas a elípticas.

Asplundia é o maior gênero da família, com cerca de 100 espécies (Eriksson 2012), distribuídas na região neotropical, com centro de diversidade no noroeste da bacia amazônica (Harling 1958). O gênero está dividido em dois subgêneros, A. subg. Choanopsis Harling com flores simétricas e $A$. subg. Asplundia Harling, com flores assimétricas (Harling 1958). No Brasil, ocorrem 21 espécies, das quais 10 são endêmicas (Leal 2012). Na Bahia, ocorrem duas espécies.

1.1. Asplundia gardneri (Hook.) Harling, Acta Horti Berg. 17: 42.1954.

Figuras 1A-C, 2A-B e 3.

Ervas terrestres, às vezes hemiepífitas escandentes, 1$2 \mathrm{~m}$ alt.; caule aéreo inconspícuo, sem raízes aéreas. Folhas alternas; bainha brilhante, ca. $12 \times 3 \mathrm{~cm}$; lâminas bífidas, pouco lustrosas, 3 nervuras por segmento, partidas de 50$60 \%$ da lâmina; segmentos lanceolados a ovados, 40-65 × 7-15 cm larg.; pecíolo 40-75 cm compr., alaranjado na base, superfície rígida, quebradiça, brilhante. Inflorescências axilares, pedúnculo 8-15 cm compr., superfície similar ao pecíolo; espádice 2,5-5 × 1,5-3 cm; espatas 3-5, dispostas ao longo do pedúnculo, $4-7 \times 1-2 \mathrm{~cm}$, às vezes com carenas ligeiramente caducas. Flores estaminadas assimétricas, 2$5 \mathrm{~mm}$ compr., receptáculo aplanado, tépalas ligeiramente caducas; estames numerosos; conectivo inconspícuo. Flores pistiladas conatas na base, $4-5 \mathrm{~mm}$ diâm., tépalas ca. 5 $\times 3 \mathrm{~mm}$; estigmas subsésseis. Infrutescências cilíndricas 4-7 × 1,5-2,5 cm, bagas livres lateralmente, conatas na base; sementes ovadas, ca. 1,2 mm compr.

Endêmica do Brasil, ocorrendo nos estados do Ceará, Piauí, Alagoas, Pernambuco, Bahia, Espírito Santo, Minas Gerais e Rio de Janeiro (Leal 2012). E6, E8, H8, I8: áreas florestais da Mata Atlântica costeira e na Serra da Chapadinha, em Lençóis, em mata de grotão a mais de 1.000 m s.n.m.

Material examinado - Almadina, fazenda Beija-flor, 19 jul. 1978 (fr.), S. Mori et al. 10272 (CEPEC); Amargosa, fazenda Timbó, mar. 1972 (fr.), A. Valeriano s.n. (ALCB 920); Arataca, PARNA Serra das Lontras, 15¹0'37''S, 30²0'28”'W, 485 m, 26 fev. 2011 (fr.), P. Leitman et al. 148 (CEPEC, RB); Camacan, fazenda Serra Bonita, 15²3'30'S, 39³3'55'W, 835 m, 2 fev. 2005 (fr.), A.M. Amorim et al. 4759 (CEPEC); Ilhéus, Castelo Novo, 15 fev. 1968 (fr.), S.G. Vinha 107 (CEPEC); Jussari, fazenda Serra do Teimoso, 1505'44”S, 39³2'33'”, 750-850 m, 15 mar. 2003 (fr.), W.W. Thomas et al. 13320 (CEPEC); Lençóis, Serra da Chapadinha, 12²7'25”'S, 4127'10”'W, 25 abr. 2005 (fr.), E. Melo et al. PCD 1793 (CEPEC, HUEFS, K); Porto Seguro, PARNA Monte Pascoal, 16²51,8'S, 37²4,8'W, 50 m, 6 fev. 1999 (fr.), W.W. Thomas et al. 12045 (CEPEC); Salvador, s.d. (fr.), A. Valeriano s.n. (RB 178669); Santa Terezinha, $12^{\circ} 15^{\prime}$ 'S, $39^{\circ} 28^{\prime} \mathrm{W}$, jun. 2000, L.P. Queiroz 6285 (HUEFS); Una, Estação Experimental Lemos Maia, 13 nov. 1980 (fr.), A. Rylands \& J.L. Hage 107 (CEPEC).

É facilmente reconhecida pela bainha e pecíolo brilhantes e quebradiços quando desidratados, com aspecto dourado e geralmente com máculas vináceas. Também apresentam as folhas conspicuamente plicadas e os pecíolos longos e sulcados. A espécie está incluída em Asplundia subg. Asplundia, caracterizado por apresentar as folhas tricostadas e as flores estaminadas assimétricas em receptáculo aplanado (Harling 1958).

\subsection{Asplundia maximiliani Harling, Acta Horti Berg. 18:} 153. 1958.

Figuras 1D, 2C/D e 3.

Hemiepífita, até $5 \mathrm{~m}$ sobre o forófito; caule curto ou inconspicuamente recoberto pelas bainhas foliares, raízes grampiformes amarronzadas. Folhas alternas, bainha verde com máculas amarronzadas, 5-10 cm compr.; lâminas bífidas, verde-opacas, 1 nervura por segmento, partidas ca. $60 \%$ da lâmina; segmentos oblanceolados, acuminados, 50 


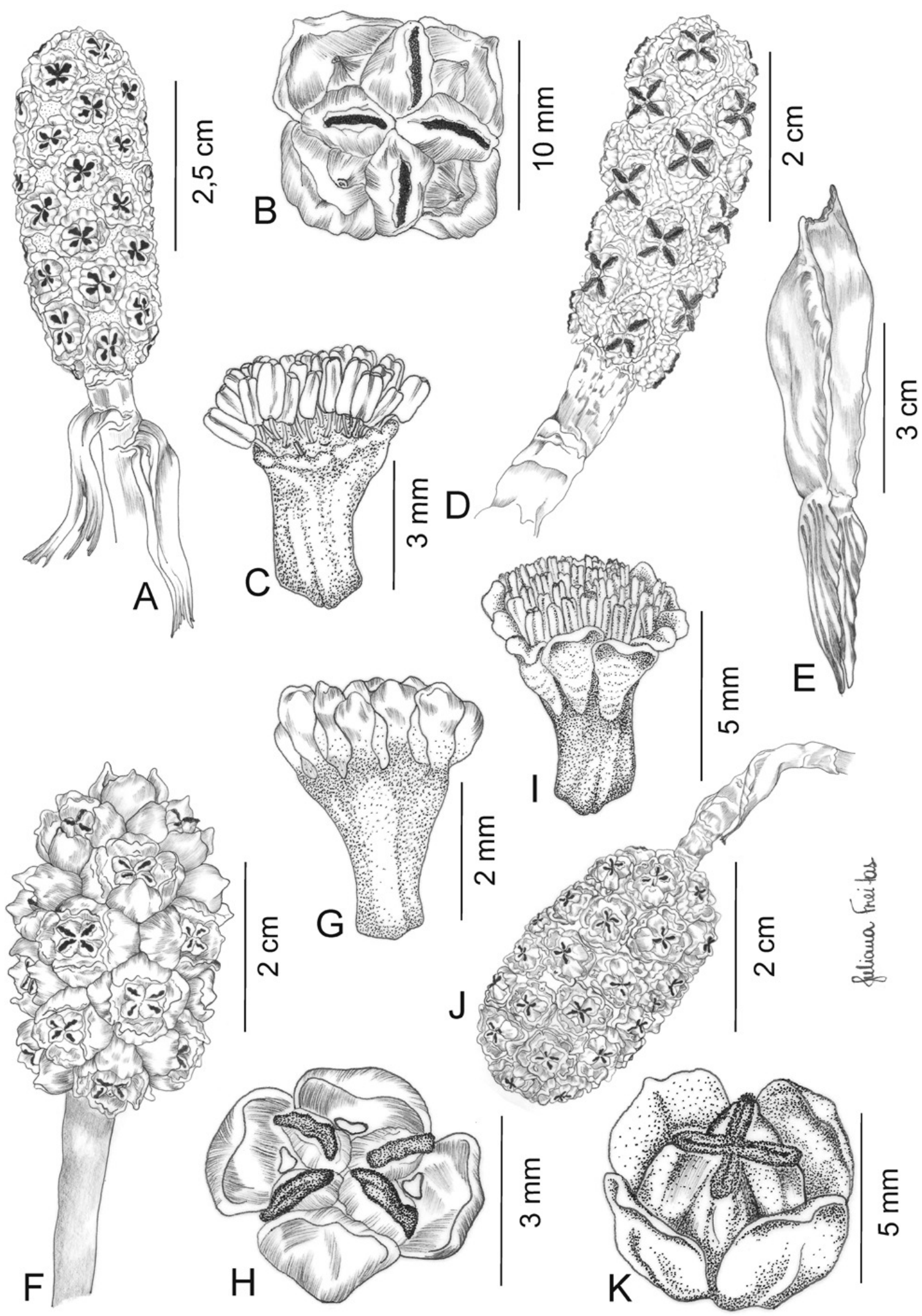

Figura 1. A-C. Asplundia gardneri: A- infrutescência; B- baga.; C- flor estaminada (Leitman 148). D. Asplundia maximiliani: infrutescência (Leitman 506). E-H. Evodianthus funifer: E- espata cimbiforme; F- infrutescência; G- flor estaminada; H- baga (Leitman 388). I-K. Thoracocarpus bissectus: I- flor estaminada; J- infrutescência; K- baga (Leitman 427). 

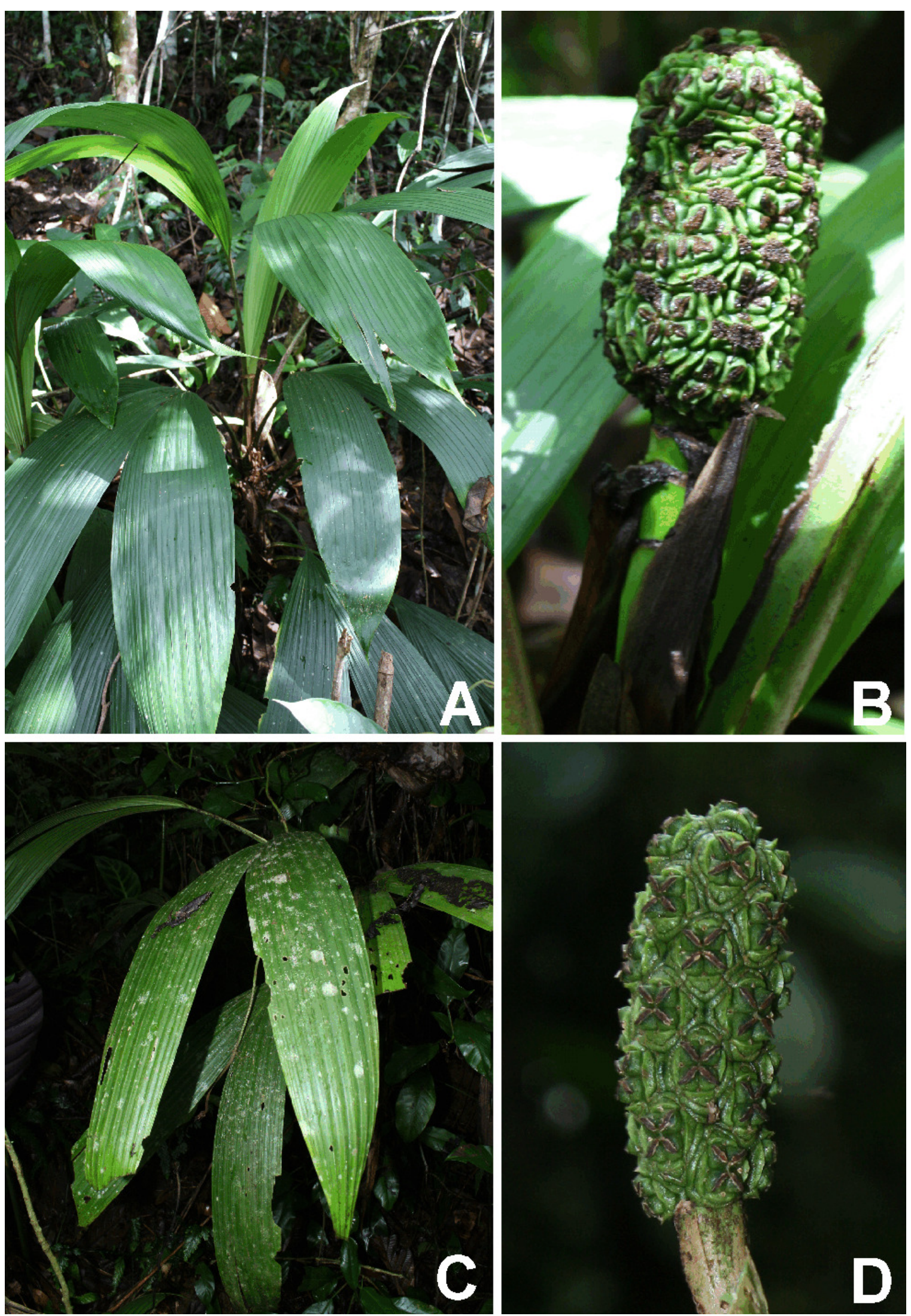

Figura 2. A/B. Asplundia gardneri: A- hábito; B- infrutescência (Leitman 148). C/D. Asplundia maximiliani: C- hábito; D- infrutescência (Leitman 506 ). 


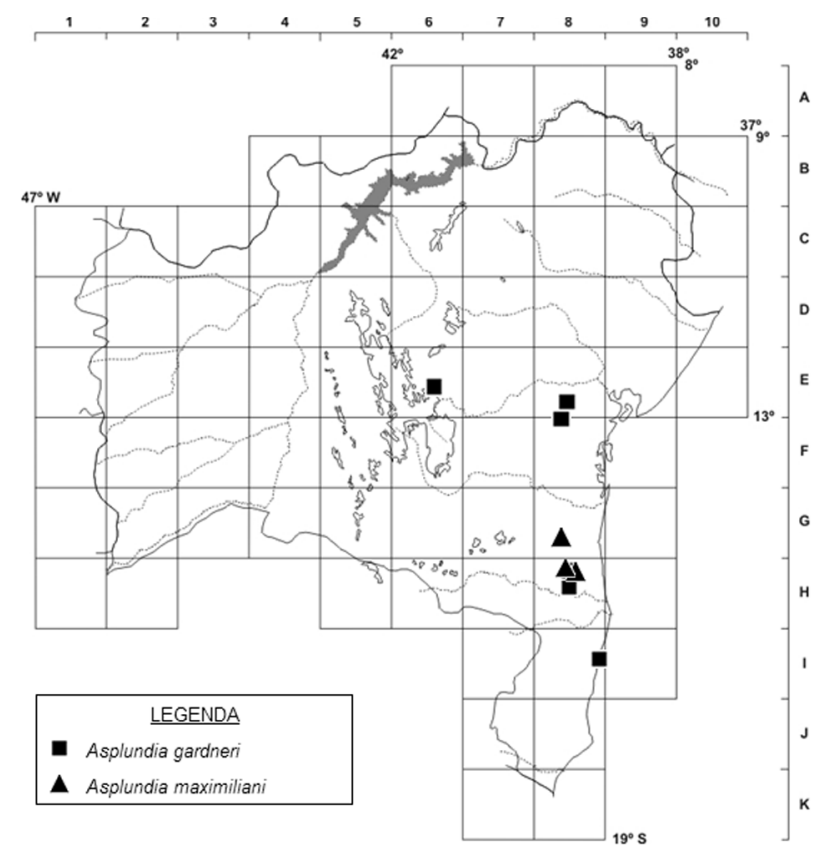

Figura 3. Distribuição de Asplundia gardneri e A. maximiliani no estado da Bahia.

$70 \times 6-8 \mathrm{~cm}$ cada; pecíolo $25-40 \mathrm{~cm}$ compr., superfície castanha, alado na porção basal. Inflorescências axilares, cilíndricas, pedúnculos 8-15 cm compr., verdes, superfície similar ao pecíolo; espádice $2-5 \times 1,5-3 \mathrm{~cm}$; espatas 4 ou 5 , cimbiformes, 5-9 $\times 1-2 \mathrm{~cm}$, dispostas ao longo do pedúnculo, carenas ausentes. Flores estaminadas simétricas, 3-4 mm compr., receptáculo côncavo; estames 20-50; conectivo inconspícuo. Flores pistiladas conatas na base, ca. $3 \mathrm{~mm}$ diâm., tépalas 2-4×1-1,5 mm; estigmas sésseis. Infrutescências cilíndricas, 3-6 × 1-2 cm, bagas livres lateralmente, conatas na base. Sementes não vistas.

Endêmica da Mata Atlântica brasileira, ocorrendo no estado da Bahia (Leal 2012) e, provavelmente no Espírito Santo. G8, H8: áreas úmidas do litoral.

Material examinado - Almadina, Serra do Corcovado, 1442'21'S, 39³6'12'W, 650-900 m, 17 dez. 2006 (fr.), R.A.X. Borges et al. 401 (CEPEC, NY, RB); Arataca, PARNA Serra das Lontras, $15^{\circ} 12^{\prime} 10^{\prime \prime} \mathrm{S}, 39^{\circ} 24^{\prime} 31^{\prime \prime} \mathrm{W}, 361-516 \mathrm{~m}, 25$ nov. 2011 (fl., fr.), P. Leitman et al. 506 (CEPEC, RB); Jussari, RPPN Serra Teimoso, 1509'16”'S, 39³1'52'S, 10 dez. 2004 (fr.), A.M. Amorim et al. 4471 (CEPEC).

A espécie é reconhecida pelas folhas verde-opacas, com apenas uma nervura principal, inflorescência com diâmetro pouco maior que o pedúnculo, espatas longas e esbranquiçadas e flores estaminadas simétricas em receptáculo côncavo. Pertence a Asplundia subg. Choanopsis, caracterizado por apresentar flores simétricas.

\section{Evodianthus Oerst.}

Lianas, ou hemiepífitas, raízes aéreas curtas ou longas, eventualmente penetrando no solo ou raramente terrestres, plantas escandentes com hastes volúveis. Folhas espiraladas, inteiras ou bífidas nos ramos jovens, bífidas nos adultos, segmentos plicados. Inflorescências terminais, subcilíndricas ou ovoides, algumas vezes subesféricas; pedúnculo relativamente longo e delgado; espatas 1-3, congestas na base da espádice. Flores estaminadas simétricas, afuniladas; tépalas livres, largo-lanceoladas a triangulares, recurvadas na antese; estames numerosos. Flores pistiladas livres, tépalas 4, bem desenvolvidas; estaminódios 4; estiletes 4; estigmas subsésseis. Sementes oblongas ou ovadas, planas, testas afiladas.

Evodianthus é um gênero monotípico, ocorrendo da Nicarágua ao Peru e Brasil (Harling et al. 1998).

\subsection{Evodianthus funifer (Poit.) Lindm., Bih. Kongl. Svenska}

Vetensk.-Akad. Handl. 26: 8. 1900.

Nome popular: cipó-verdadeiro (sul da Bahia).

Figuras 1E-H, 4A-C e 5.

Hemiepífita, até $5 \mathrm{~m}$ compr. sobre o forófito; caule inconspícuo; raízes aéreas e grampiformes acinzentadas. Folhas espiraladas, bainha amplexicaule, esverdeadas, 9$12 \times 2-3 \mathrm{~cm}$ compr.; lâminas bífidas, brilhantes, partidas 50-75\%(-90\%), 1 nervura, segmentos plicados, linearlanceolados, 30-70 × 4-8 cm; pecíolo 25-40 cm compr., canaliculado ou sulcado na base, verde. Inflorescências terminais; pedúnculo 15-18 cm compr., superfície semelhante ao pecíolo; espádice $2-5 \times 1-3 \mathrm{~cm}$, subcilíndrico ou ovoide, às vezes subesférico; espatas $1-3$, congestas na base da espádice, 3-6 $\times$ ca. $2 \mathrm{~cm}$, cimbiformes, caducas. Flores estaminadas simétricas, $4-5 \times 2-3 \mathrm{~mm}$, receptáculo côncavo; estames 10-30, adnatos às tépalas, quando jovens totalmente protegidos por elas, conectivo inconspícuo. Flores pistiladas livres, 3-5 mm diâm.; tépalas 5-10 × 2-4 mm, estaminódios filiformes, epitépalos, 5-10 cm compr., cedo caducos. Infrutescências cilíndricas ou subesféricas, 1,54,5 $\times 1-2,5 \mathrm{~cm}$; bagas livres. Sementes estreitamente ovadas.

No Brasil, ocorre em toda a bacia amazônica e na Mata Atlântica, nos estado da Bahia e Espírito Santo (Leal 2010). F8, G8, H8, I8, J8: florestas de galerias ou matas de terras baixas.

Material examinado - Amargosa, Serra do Timbó, 1310'20”S, 3909'34”W, 26 jan. 2007 (fr.), D. Cardoso et al. 1623 (CEPEC, HUEFS); Arataca, PARNA Serra das Lontras, $15^{\circ} 11^{\prime} 46$ 'S $, 39^{\circ} 23^{\prime} 30^{\prime \prime} \mathrm{W}, 381-712 \mathrm{~m}, 11$ set. 2011 (fl.), P. Leitman et al. 388 (RB); Cairu, rod. Nilo Peçanha/Cairu, 13³3'47's, 3903"37”W, 13 nov. 2003 (fl., fr.), J.L. Paixão et al. 318 (CEPEC, RB); Eunápolis, 23 jun. 1967 (fr.), A. Castellanos 26436 (CEPEC); Guaratinga, fazenda Vitória, 16²43'S, 3946’W, 29 out. 1979 (fr.), L.A. Mattos-Silva \& H.S. Brito 640 (CEPEC); Igrapiúna, sítio Rodotec, 1349'S, 39 08'W, 21 dez. 2003 (fr.), L.M.N. Meyer et al. 12 (ALCB); Ilhéus, $2 \mathrm{~km} \mathrm{NNE} \mathrm{do} \mathrm{banco} \mathrm{da} \mathrm{Vitória} \mathrm{na} \mathrm{estrada}$ para o limite oeste de Mata da Esperança, 144' $38^{\circ}$ 'S, 39 $05^{\circ} 28^{\prime \prime} \mathrm{W}$, 28 set. 1994 (fr.), W.W. Thomas et al. 10652 (CEPEC, NY, RB); Itabuna, fazenda Santa Clara, 12 ago. 1972 (bot.), R.S. Pinheiro 1926 (CEPEC); Itacaré, ramal da torre da Embratel, 6 jun. 1978 (fr.), S.A. Mori \& T.S. Santos 10113 (CEPEC); Itambé, rod. Itaimbé, Km 3 a 4 para Itamaria, 12 nov. 1971 (fl.), T.S. Santos 2124 (CEPEC); Itapebi, fazenda Lombardia, 15²1'29'S, 39³2' 18' W, 290-516 m, 22 nov. 2006 (fr.), A.P. Fontana et al. 2530 (MBM, 

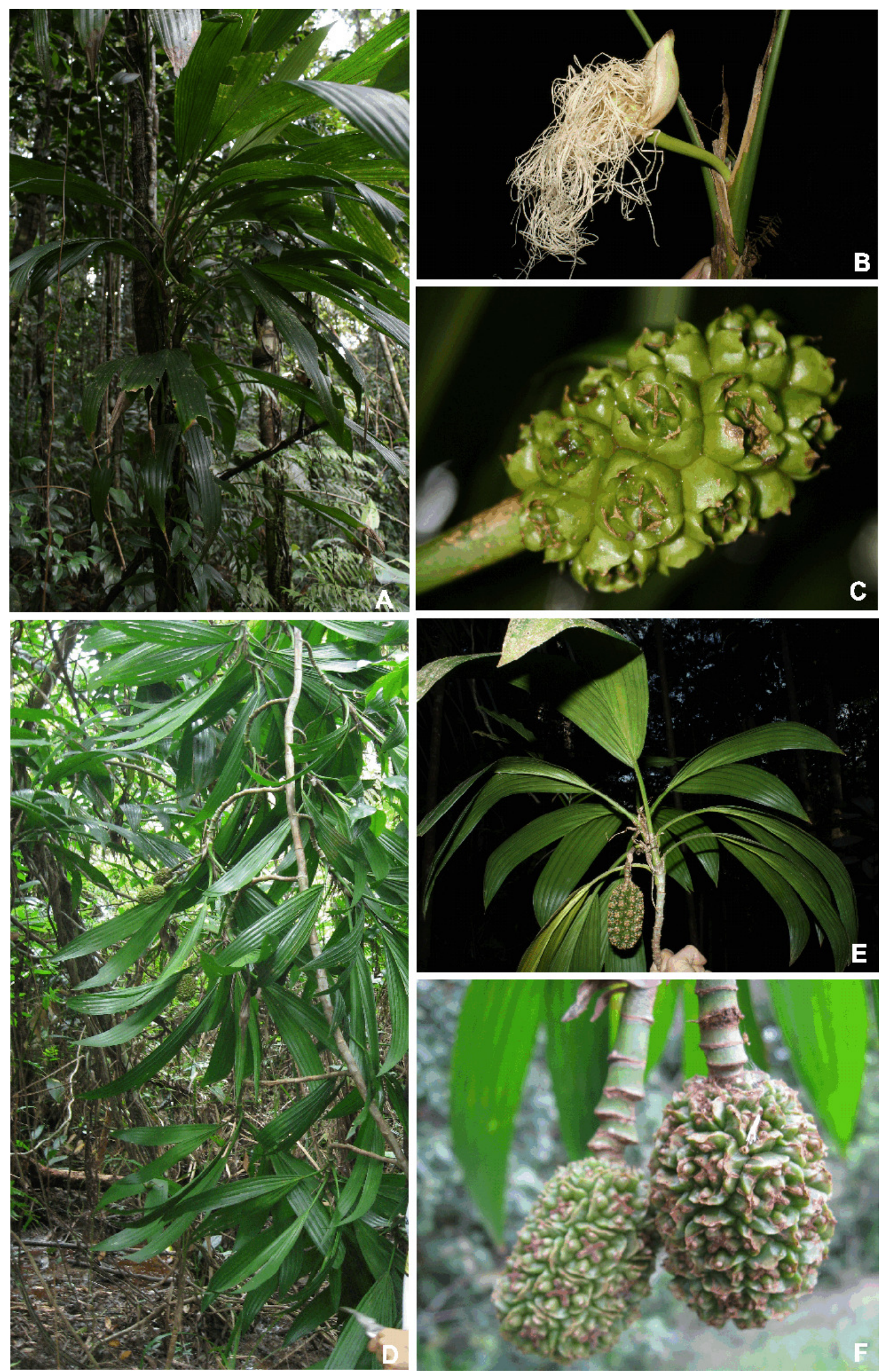

Figura 4. A-C. Evodianthus funifer: A- hábito; B- inflorescência; C- infrutescência (Leitman 388). D-F. Thoracocarpus bissectus: D- hábito; E- ramo com fruto; F- infrutescência (Leitman 427). 


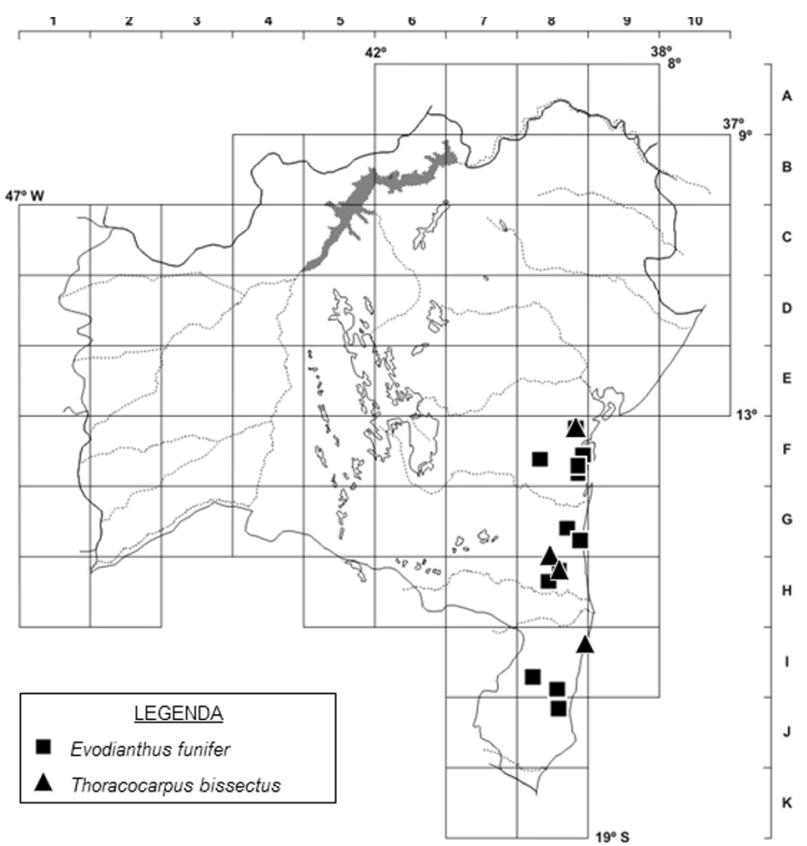

Figura 5. Distribuição de Evodianthus funifer e Thoracocarpus bissectus no estado da Bahia.

RB); Ituberá, fazenda Pupunha da Itapema II, $13^{\circ} 43$ ' S, 39 $08^{\circ}$ 'W, 20 dez. 2003 (fr.), L.O. Magalhães et al. 5 (ALCB, CEPEC); Maraú, rod. BR-030, trecho Ubaitaba/Maraú, Km 33, 5 fev. 1979 (fr.), S.A. Mori et al. 11353 (CEPEC); Nova Viçosa, área de restinga, 22 jul. 1979 (fr.), V.L. Gomes 42 (RB); Porto Seguro, Parque Nacional de Monte Pascoal, 16 ${ }^{\circ} 53^{\prime}$ 'S, 39 $25^{\circ} \mathrm{W}, 100-200 \mathrm{~m}, 11$ jan. 1977 (fr.), R.M. Harley et al. 17823 (CEPEC, K, NY, RB, UEC); Prado, Km 21 da estrada para Itamajaru de Prado, 17010'S, 39²4'W, 9 fev. 1993 (fr.), J.A. Kallunki \& J.R. Pirani 470 (CEPEC); Salvador, s.d. (fr.), A. Valeriano s.n. (RB 427174); Santa Cruz Cabrália, Estação Ecológica do Pau Brasil, 25 nov. 1987 (fl.), P.J.M. Maas et al. 6991 (CEPEC, RB); Una, Estação Experimental Lemos Maia, 11 nov. 1980 (fl. e fr.), A. Rylands \& J.L. Hage 55 (CEPEC, INPA, RB); Uruçuca, EMARC, Reserva Gregório Bowdar, 14³6'12”S, 39¹7'03”'W, 4 abr. 2002 (fr.), A.M. Carvalho et al. 7159 (CEPEC, NY, RB); Wenceslau Guimarães, fazenda Condomínio União, 13³7'S, 3940'W, 220 m., 1 jun. 1991 (fr.), S.J. Mayo \& F.A. Carvalho 879 (CEPEC).

A espécie é reconhecida especialmente pelas inflorescências terminais, com longos e densos estaminódios esbranquiçados e filiformes formando tufos, além das espatas chamativas, carenas geralmente coloridas e folhas brilhantes.

\section{Thoracocarpus Harling}

Lianas ou ervas terrestres; caules ramificados; raízes grampiformes, raízes aéreas pendentes, eventualmente penetrando no solo. Folhas espiraladas, ramos jovens com folhas inteiras ou bífidas e ramos adultos com folhas bífidas. Inflorescências axilares, cilíndricas ou elipsoides, brilhantes na fase dos frutos maduros, verde-oliva ou verdes a castanho-amareladas; espatas 8-11, mal distribuídas, sucessivamente menores para a base. Flores estaminadas simétricas, receptáculo profundamente côncavo; lobos do perianto
10-15, simetricamente dispostos ao redor do receptáculo, conatos em mais da metade do seu comprimento, glandulíferos; estames numerosos. Flores pistiladas conatas na base; tépalas 4, conatas na base; estiletes 4, inconspícous; estigmas sésseis. Sementes oblongas, planas e finas, amareladas, minuciosamente estriadas.

Thoracocarpus é um gênero monotípico, com distribuição na América Central (Costa Rica e Panamá) e América do Sul, incluindo Colômbia, Venezuela, Guiana, Guina Francesa, Suriname, Equador, Peru, Bolívia e Brasil (Harling \& Eriksson 1998).

\subsection{Thoracocarpus bissectus (Vell.) Harling, Acta Horti}

Berg. 18: 255. 1958.

Figuras 1I-K, 4D-F e 5.

Lianas, caules até 20 m compr.; raízes aéreas pendentes, acinzentadas ou vináceas, raízes grampiformes curtas, amarronzadas; caule densamente anelado por cicatrizes foliares. Folhas espiraladas, ramos jovens com folhas inteiras, lâmina 5-10 × 2-4 cm, ramos adultos com folhas bífidas, lâmina $25-45 \times 3,5-5 \mathrm{~cm}$, partidas até ca. $50 \%$ da lâmina, verde-brilhantes, nervura 1; segmentos lanceolados, brilhantes; pecíolo verde, brilhante, $10-15 \mathrm{~cm}$ compr. Inflorescências axilares, pedúnculo $8-10 \mathrm{~cm}$ compr.; espádice 2-8 × 1,5-3 cm, cilíndrico; espatas 6-8(-11), distribuídas ao longo do pedúnculo, $3-5 \times 1-4 \mathrm{~cm}$, cimbiformes, às vezes com carena. Flores estaminadas simétricas, $4-8 \times$ 3-6 mm, receptáculo côncavo; estames 20-35, protegidos pelas tépalas; conectivos inconspícuos. Flores pistiladas ca. $6 \mathrm{~mm}$ diâm., tépalas ca. $5 \times 3 \mathrm{~mm}$; estaminódios envoltos pelas tépalas e adnatos à base destas. Infrutescências cilíndricas, 2,5-7 × 1,5-2,5 cm; bagas livres. Sementes ca. 1 mm compr.

No Brasil, é comum nas áreas Central e Oriental da Amazônia (Gomes \& Melo-Silva 2006) e, na Mata Atlântica litorânea, se estende de Pernambuco ao Sul de São Paulo (Leal 2012). F8, H8, I9: Mata Atlântica.

Material examinado - Amargosa, Serra do Timbó, 1310'20”'S, 3909'34”'W, 26 jan. 2007 (fl.), D. Cardoso et al. 1632 (CEPEC, HUEFS); Arataca, PARNA Serra das Lontras, $15^{\circ} 12^{\prime} 17^{\prime}$ 'S, 39²2' 52''W, 523-604 m, 12 set. 2011 (fr.), P. Leitman et al. 427 (CEPEC, RB); Belmonte, distrito de Barrolândia, 27 jul. 1988 (fr.), T.S. Santos et al. 4413 (CEPEC); Itacaré, ramal da torre da Embratel, 21 jul. 1984 (fr.), A.M. Carvalho et al. 2098 (CEPEC); Jussari, RPPN Serra do Teimoso, 21 abr. 1999 (fr.), A.M.A. Amorim et al. 2916 (CEPEC, SP); Porto Seguro, RPPN Manona, 20 dez. 2005 (fr.), L.J. Alves 119 (ALCB, MBM); São Sebastião do Passé, Mata da Mariquita, jun. 2009., C.S. SilvaLima s.n. (HUNEB); Santa Cruz Cabrália, Estação Vera Cruz,

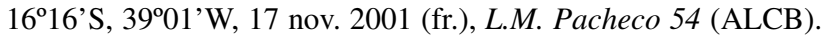
Una, Estação Experimental Lemos Maia, 27 ago. 1980 (est.), A. Rylands 25 (CEPEC).

É reconhecida especialmente pelo hábito lianescente, com longos e congestos ramos convergindo do dossel para o solo, folhas brilhantes e inflorescências pêndulas. 


\section{Agradecimentos}

À Fundação de Amparo à Pesquisa do Estado da Bahia (FAPESB) e Conselho Nacional de Desenvolvimento Científico e Tecnológico (CNPq), pelo financiamento dos projetos Flora da Bahia (FAPESB APR 162/2007; CNPq Proc.
562278/2010-9 e 483909/2012) e REFLORA (Proc. 563858/

2010-5). Aos curadores dos herbários visitados, pela disponibilidade do material. À Paula Leitman pelas fotografias. Os autores agradecem, ainda, ao CNPq, pelas bolsas concedidas a JGF, ESL (mestrado), AMG (PQ1-A) e RPO (PQ2).

\section{REFERÊNCIAS}

Beck, H.T. 2004. Cyclanthaceae. In: N. Smith, S.A. Mori, A. Henderson, D.Wm. Stevenson \& S.V. Heald (eds), Flowering Plants of the Neotropics. Princeton University Press, Princeton, p. 431-432.

Eriksson, R. 2012. Cyclanthaceae. In: W. Milliken, B. Klitgård \& A. Baracat (eds), Neotropikey - Interactive Key and Information Resources for Flowering Plants of the Neotropics. Disponível em http://www.kew.org/science/tropamerica/neotropikey/ families/Cyclanthaceae.htm; acesso em mar. 2012.

Gomes, F.P. \& Mello-Silva, R. 2006. Flora da Reserva Ducke, Amazonas, Brasil: Cyclanthaceae. Rodriguésia 57: 159-170.

Harling, G. 1958. Monograph of the Cyclanthaceae. Acta Horti Bergiani 18: 1-428.

Harling, G. \& Eriksson, R. 1998. Cyclanthaceae. In: J.A. Steyermark, P.E. Berry \& B.K. Holst (eds), Flora of the Venezuelan Guayana. (Caesalpiniaceae-Ericaceae). Vol. 4. Missouri Botanical Garden Press, St. Louis, p. 471-486. 11

Harling, G.; Wilder, G.J. \& Eriksson, R. 1998. Cyclanthaceae. In: K. Kubitzki (ed.), The Families and Genera of Vascular
Plants. Flowering plants Monocotyledons - Lilianae (except Orchidaceae). Vol. 3. Springer Verlag, Berlin, p. 202-215.

Leal, E.S. 2010. Cyclanthaceae. In: R.C. Forzza, J.F.A. Baumgratz, C.E.M. Bicudo, A.A. Carvalho Jr., A. Costa, D.P. Costa, M. Hopkins, P.M. Leitman, L.G. Lohmann, L.C. Maia, G. Martinelli, M. Menezes, M.P. Morim, M.A.N. Coelho, A.L. Peixoto, J.R. Pirani, J. Prado, L.P. Queiroz, V.C. Souza, J.R. Stehmann, L.S. Sylvestre, B.M.T. Walter \& D. Zappi (eds), Catálogo de Plantas e Fungos do Brasil. Vol. 2. Andrea Jakobsson Estúdio/Jardim Botânico do Rio de Janeiro, Rio de Janeiro, p. 902-903.

Leal, E.S. 2012. Cyclanthaceae. In: Lista de Espécies da Flora do Brasil. Jardim Botânico do Rio de Janeiro. Disponível em http:/ /floradobrasil.jbrj.gov.br/2012/FB000098; acesso em mar. 2012.

Leitman, P. \& Leal, E.S. 2009. Cyclanthaceae. In: J.R. Stehmann, R.C. Forzza, A. Salino, M. Sobral, D.P. Costa \& L.H.Y. Kamino (eds), Plantas da Floresta Atlântica. Jardim Botânico do Rio de Janeiro, Rio de Janeiro.

\section{Lista de Exsicatas}

Alves, L.J. 119 (3.1); Amorim, A.M.A. 2910 (1.1), 2916 (3.1), 4471 (1.2), 4759 (1.1), 6438 (2.1); Borges, R.A.X. 401 (1.2); Cardoso, D. 1623 (2.1), 1632 (3.1); Carvalho, A.M. 2098 (3.1), 3375, 3579, 3659, 4449, 7159 (2.1); Castellanos, A. 26436 (2.1); Costa, L.C.B. 186 (2.1); Eupunino, A. 23 (2.1); Fiaschi, P. 2674 (2.1); Fontana, A.P. 2530 (2.1); Forzza, R.C. 6433 (1.1); Giulietti, A.M. PCD 1581 (1.1); Gomes, V.L. 42 (2.1); Guedes, M.L. s.n. ALCB: 3186, 5250, 6679, 9289 (2.1), 26570 (3.1); Hage, J.L. 135 (2.1); Harley, R.M. 17182, 17823, 18225 (2.1); Heringer, E.P. 3302 (2.1); Kallunki, J.A. 470, 530 (2.1); Leitman, P. 124, 125 (2.1), 131 (1.1); 133 (2.1), 148, 196, 213 (1.1), 388 (2.1), 427 (3.1), 506 (1.2); Lopes, M.M.M. 1464 (1.1); Loureiro, D.M. 423 (2.1); Maas, P.J.M. 6991, 7067 (2.1); Magalhães, L.O. 5 (2.1);
Mattos-Silva, L.A. 640 (2.1); 2150 (3.1), 3674 (2.1); Mayo, S.J. 879 (2.1); Mello-Filho, L.E. 2944 (2.1); Melo, E. PCD 1793 (1.1); Meyer, L.M.N. 12 (2.1); Mori, S. 10113 (2.1), 10272 (1.1), 10655, 11012, 11067, 11353, 11876, 12089 (2.1); Pacheco, L.M. 54 (3.1); Paixão, J.L. 318 (2.1); Paraguassu, L.A.A. 511 (2.1); Pengel, H.O. 16 (1.1); Pinheiro, R.S. 1926 (2.1); Ramos, C.E. 78 (2.1); Roque, N. PCD 2203 (1.1.); Rylands, A. 25 (3.1), 55 (2.1), 107 (1.1); Santos, T.S. 448 (2.1), 1895 (3.1), 1931, 2124 (2.1), 4413 (3.1); Santos, F.S. 361, 624 (2.1); Silva-Lima, C.S. s.n. (3.1); Sobral, M. 5809 (2.1); Valadão, R.M. 369, 370, 384 (2.1); Valeriano, A. s.n. ALCB 920, s.n. RB: 178669 (1.1), 427174 (2.1); Vinha, S.G. 107 (1.1); 108 (2.1); Voeks, R. 357 (3.1); Thomas, W.W. 10163, 10652 (2.1), 12045, 13320 (1.1). 